\title{
PROBIÓTICOS E PREBIÓTICOS NA ATENÇÃO PRIMÁRIA AO CÂNCER DE CÓLON
}

\author{
Fabiana Gouveia DENIPOTE¹, Erasmo Benício Santos de Moraes TRINDADE² e \\ Roberto Carlos BURINI ${ }^{3}$
}

\begin{abstract}
RESUMO - Contexto - As neoplasias de cólon são a terceira forma mais comum de câncer atualmente. Seus tratamentos ainda estão associados a elevado risco de complicações, ressaltando, assim, a necessidade de elaborar novas estratégias de tratamento. A ingestão de probióticos, prebióticos ou a combinação de ambos (simbióticos), representa nova opção terapêutica. Diante da importância do equilíbrio quantitativo e qualitativo da microbiota intestinal para saúde humana e com objetivo de melhor elucidar o papel dos probióticos e prebióticos, o tema citado procura abordar a importância destes como coadjuvantes na prevenção e tratamento de câncer de cólon. Metodologia - Foi realizada pesquisa em bancos de dados científicos (Medline, Lilacs, PubMed, Ovid, Scielo) através de levantamento de artigos científicos, além da busca direta aos periódicos, priorizando-se os mesmos do período de 2003 a 2008. Foram, também, coletadas informações através de sites da internet, como forma de melhor compreender a epidemiologia, conceitos e tratamentos dessa patologia. Resultados - Estudos apontam relação inversa entre o consumo de probióticos e prebióticos e o diagnóstico de câncer de cólon, sendo que alguns dos possíveis mecanismos englobam: aumento da resposta imune, redução da resposta inflamatória, inibição de formação de células tumorais e da conversão de substâncias pré-carcinogênicas em carcinogênicas. Conclusão - Através da realização desta revisão literária foi possível obter respostas positivas quanto ao uso de probióticos e prebióticos na carcinogênese, colocando seu uso como recomendado de forma adequada.
\end{abstract}

DESCRITORES - Probióticos. Prebióticos. Simbióticos. Neoplasias do cólon.

\section{PROBIÓTICOS, PREBIÓTICOS E SIMBIÓTICOS}

O termo probiótico é derivado do grego, significando "para a vida". Foi primeiramente utilizado por Lilly e Stillwell(39), em 1965, e vem recebendo muitas denominações conceituais. Entretanto, a definição aceita internacionalmente é que probióticos são microrganismos vivos, administrados em quantidades adequadas, que conferem benefícios à saúde do hospedeiro ${ }^{(55)}$. Bactérias pertencentes ao gênero Lactobacillus, como Lactobacillus rhamnosus GG, e Bifidobacterium e, em menor escala, Enterococcus faecium, assim como os fermentados Saccharomyces boulardii são mais frequentemente empregadas como suplementos probióticos para alimentos, uma vez que elas têm sido isoladas de todas as porções do trato gastrointestinal do humano saudável ${ }^{(11)}$. A correção das propriedades da microbiota autóctone desbalanceada constitui a racionalidade da terapia por probióticos ${ }^{(34)}$. Estes, promovem diversos efeitos benéficos ao hospedeiro, tais como: fermentação de substratos, resultando na produção dos ácidos graxos de cadeia curta (AGCC); redução do pH, que exerce ação bactericida; diminuição dos níveis séricos de amônia pela fermentação de proteínas; participação na produção de vitaminas do complexo B; influência na resposta imune e redução dos níveis de triglicerídio sérico $^{(6,45)}$. Admite-se que no intestino os probióticos sejam capazes de ocupar nichos da mucosa, impedindo desse modo patógenos de ocuparem esses sítios. Além disso, as bacteriocinas, produzidas a partir de componentes protéicos dos lactobacilos, são capazes de exercer ação local semelhante aos antibióticos contra organismos patogênicos e de diminuir a produção de citocinas pró-inflamatórias, tais como o interferongama, fator de necrose tumoral-alfa e interleucina 2. Também apresentam capacidade de estimular a produção da imunoglobulina $\mathrm{A}$, conforme estímulo de sua produção com o uso do lactobacilos casei CRL 431, indicando ativação do sistema autoimune. Os probióticos são, geralmente, administrados em situações de distúrbios intestinais, promovidos por fatores específicos, dentre os quais têm-se: dietas inadequadas, alguns medicamentos que não sejam

\footnotetext{
${ }^{1}$ Curso de Especialização em "Cuidados Nutricionais do Paciente e do Desportista", Faculdade de Medicina de Botucatu, Universidade Estadual Paulista - UNESP, 2 Universidade Federal de Santa Catarina, Florianópolis, SC; ${ }^{3}$ Departamento de Saúde Pública da Faculdade de Medicina de Botucatu, UNESP, Botucatu, SP.

Correspondência: Nutr. Fabiana Gouveia Denipote - Centro de Metabolismo em Exercício e Nutrição (CeMENutri) - Faculdade de Medicina de Botucatu - $18618-970$

Rubião Júnior, Botucatu, SP. E-mail: fafagd@yahoo.com
} 
antibióticos, desequilíbrios clínicos, cirurgias do aparelho digestivo, enfim, situações que promovam ruptura da flora do trato gastrointestinal e, por consequência, tornando o hospedeiro suscetível a doenças como, por exemplo: diarreia induzida pelo uso de antibióticos, colite pseudomembranosa, supercrescimento bacteriano do intestino delgado ${ }^{(35)}$.

O termo prebiótico foi introduzido por Gibson e Roberfroid $^{(18)}$, em 1953, e foi definido como sendo um ingrediente alimentar não digerido, que resulta em benefício ao hospedeiro pela estimulação seletiva do crescimento e/ ou ativação do metabolismo de uma ou de um número limitado de bactérias no cólon. Também são definidos como substâncias constituídas essencialmente por carboidratos de tamanhos diferentes, desde composição mono, dissacárides, oligossacárides, até grandes polissacárides, que constituem suplementos alimentares não hidrolisáveis nem absorvidos no intestino delgado, sendo disponibilizados para auxiliar as bactérias endógenas, favorecendo-as em seu crescimento e metabolismo probiótico, principalmente os lactobacilos e as bifidobactérias ${ }^{(35)}$. Dentre os prebióticos, têm-se os frutooligossacarídeos (FOS) ou oligofrutoses resistentes, isto é, carboidratos complexos de configuração molecular que os tornam resistentes à ação hidrolítica da enzima salivar e intestinal, atingindo, intactos, o cólon. O FOS é formado a partir da hidrólise da inulina e desempenha diversas funções fisiológicas no organismo, como alteração do trânsito intestinal, promovendo: redução de metabólitos tóxicos, prevenção de câncer de cólon, redução do colesterol plasmático e da hipertrigliceridemia, melhora da biosdisponibilidade de minerais, além de contribuir para o aumento da concentração das bífidobactérias no cólon ${ }^{(18)}$. Estão presentes na cebola, chicória, alho, lecitinas (proteínas vegetais), alcachofra, cereais, aspargos, raízes de almeirão, beterraba, banana, trigo e tomate. Podem ser encontrados, também, no mel e açúcar mascavo, em tubérculos, como o yacon, e em bulbos $^{(44)}$. Alguns efeitos atribuídos aos prebióticos são a modulação de funções fisiológicas chaves, como a absorção de cálcio, diminuindo o risco de osteoporose, metabolismo lipídico, modulação da composição da micriobiota intestinal e a redução do risco do câncer de cólon ${ }^{(50)}$. Existem vários estudos que comprovam os efeitos benéficos da ingestão de prebióticos como os FOS. Eles melhoram o metabolismo da bifidobacteria e diminuem o pH do intestino grosso, destruindo bactérias putrefativas. A acidificação do meio ocorre com a produção dos ácidos graxos de cadeia curta e com o aumento da produção das bactérias produtoras de ácido láctico. Já a diminuição no número de bactérias nocivas (como Escherichia coli, Clostridium, Streptococcus faecallis e Proteus) tem como consequência o decréscimo de metabólitos tóxicos como amônia, indol, fenóis e nitrosaminas. Ainda se pode observar aumento da digestão e metabolismo da lactose, aumento de reciclagem de compostos como o estrógeno, aumento da produção de compostos imunoestimulantes, que possuem atividade antitumoral, diminuição do crescimento de bactérias nocivas, diminuição da produção de toxinas e compostos carcinogênicos. Atribui-se, também, ao consumo de FOS a redução da potencialidade de várias enfermidades humanas normalmente associadas com o alto número de bactérias intestinais patógenas, como doenças autoimunes, câncer, acne, cirrose hepática, constipação, intoxicação alimentar, diarreia associada a antibióticos, distúrbios digestivos, alergias e intolerâncias a alimentos e gases intestinais ${ }^{(62)}$. A utilização de bifidobactérias e de lactobacilos é sugerida como estratégia terapêutica eficaz em casos de diarreia, por excluir as bactérias patogênicas na competição pelos sítios de ligação na mucosa intestinal e na disponibilidade de substratos. Além disso, atuam também por sua capacidade de secretar substâncias bactericidas como resultado do processo de fermentação, afastando o patógeno invasor, bem como impedindo a adesão destas bactérias à mucosa intestinal ${ }^{(33)}$.

Da ação sinérgica dos probióticos auxiliados pelas substâncias prebióticas se estabelecem os simbióticos, ou seja, a interação entre o probiótico e o prebiótico, a qual in vivo, pode ser favorecida por uma adaptação do probiótico ao substrato prebiótico. O consumo de probióticos e de prebióticos selecionados apropriadamente pode aumentar os efeitos benéficos de cada um deles, uma vez que o estímulo de cepas probióticas conhecidas leva à escolha dos pares simbióticos substrato-microrganismos ideais ${ }^{(5,27,40)}$. A colonização de probióticos exógenos combinados com os prebióticos pode aumentar a ação dos primeiros no trato intestinal. Possíveis indicações dos simbióticos em situações clínicas, nas quais existem indícios de sua eficácia são: diarreia viral aguda, diarreia dos viajantes, infecções e complicações gástricas pelo Helicobacter pylori, encefalopatia hepática, diarreia em pacientes portadores da síndrome da imunodeficiência adquirida, síndrome do intestino irritável, diarreia em pacientes em nutrição enteral por sonda nasogástrica, radioterapia envolvendo a pelves, doença inflamatória intestinal, carcinogênese, alergia, síndrome da resposta inflamatória sistêmica, constipação, melhoria da saúde urogenital de mulheres, redução do colesterol e triacilglicerol plasmático, efeitos benéficos no metabolismo mineral, particularmente densidade e estabilidade óssea ${ }^{(35,56)}$. Nessas situações clínicas, o objetivo com o uso da terapia probiótica e prebiótica é o de aumentar o número e a atividade desses microorganismos, com supostas propriedades promotoras de saúde, visando oferecer condições para que a flora normal se recomponha.

\section{O SISTEMA DIGESTÓRIO - ANATOMIA E MICROBIOTA}

Em seguida ao aparelho respiratório, o sistema gastrointestinal representa a segunda maior área de superfície corporal, medindo em torno de $250 \mathrm{~m}^{2}$ a $400 \mathrm{~m}^{2}$, constituindo importante linha de proteção do organismo contra o meio externo ${ }^{(2,58)}$. A superfície interna do intestino delgado parece lisa e escorregadia, mas vista através do microscópio, é enrugada em centenas de dobras. Cada dobra é contornada por centenas de projeções denominadas vilosidades, cujas células reconhecem e selecionam os nutrientes de que o corpo precisa e regulam sua absorção. Nas fissuras entre as vilosidades estão as criptas — glândulas tubulares responsáveis pela secreção de alguns produtos intestinais. Associados ao epitélio secretor encontram-se os 
linfócitos intra-epiteliais, participantes da defesa imunitária local. Adicionalmente, as secreções do trato gastrointestinal — saliva, muco, ácido gástrico e enzimas digestivas — não só promovem a digestão, como defendem o organismo contra microorganismos presentes nos alimentos ${ }^{(59,60)}$.

A proliferação rápida das células da mucosa do sistema digestório torna-as especialmente vulneráveis à quimioterapia, resultando em mucosites, ulcerações e diminuição da capacidade de absorção ${ }^{(13)}$.

O intestino é, portanto, estrutura complexa, formada principalmente por três componentes que estão em contato permanente e se relacionam entre si: as células intestinais, os nutrientes e a microbiota ${ }^{(7)}$.

O sistema digestório abriga flora com mais de 500 espécies de bactérias e cuja distribuição não é homogênea ao longo de sua extensão. $\mathrm{O}$ estômago e o intestino delgado contêm poucas espécies tanto aderidas ao seu epitélio, como livres no seu lúmen. Já o cólon contém complexo e dinâmico ecossistema microbiótico, com grande concentração de bactérias, chegando a atingir mais de $10^{11}$ a $10^{12}$ unidades formadoras de colônia por mililitros ${ }^{(4,23)}$. Dentre elas estão as bifidobactérias e lactobacilos, consideradas bactérias não-patogênicas ou benéficas, pois desempenham atividades biológicas positivas na saúde humana e, por isso, são alvos comuns das intervenções dietéticas ${ }^{(12)}$.

Os componentes da dieta são alguns dos vários fatores que influenciam a população de bactérias e seu meio ambiente. Por exemplo, as bactérias do trato intestinal digerem as fibras dietéticas, produzindo os ácidos graxos de cadeia curta que os colonócitos utilizam para fins energéticos. Adicionalmente, as bactérias hidrolisam a ureia proveniente do fígado, gerando a amônia $\left(\mathrm{NH}_{3}^{+}\right)$, a partir dela, sintetizam os aminoácidos de que necessitam ${ }^{(60)}$.

Estas bactérias sintetizam várias vitaminas (biotina, folato, vitamina B6, B12), incluindo quantidade significativa de vitamina $\mathrm{K}$, embora insuficiente para satisfazer as necessidades totais do corpo $^{(60)}$.

A homeostase destas comunidades bacterianas é mantida pelo equilíbrio que é determinado pelos próprios microorganismos desse ambiente ${ }^{(1,41)}$.

Estudos in vitro e in vivo têm demonstrado que o ecossistema bacteriano intestinal normal representa barreira extremamente efetiva, em oposição a microorganismos patogênicos e oportunistas, através do equilíbrio entre as espécies de bactérias residentes ${ }^{(16,28)}$. Assim, situações de desequilíbrio entre espécies podem representar potencial ameaça para o surgimento de diversas doenças, associadas ou não à diminuição da defesa imunológica do hospedeiro ${ }^{(3)}$. A competição por nutrientes e espaço, a inibição de um grupo bacteriano através dos produtos metabólicos de outro e, ainda, predação e parasitismo, geralmente contribuem para o equilíbrio das populações ${ }^{(1,41)}$.

Logo, a flora intestinal pode proteger os indivíduos contra infecções. Por outro lado, o distúrbio dessas populações de microorganismos, como nas diarreias agudas ou nas intervenções dietéticas restritivas, pode romper esse equilíbrio e aumentar a suscetibilidade às infecções, como Clostridium difficile (associado com colites pseudomembranosas) e presença de Shigella, Vibrio cholera, Escherichia coli patogênica, Campylobacter e rotavírus, que ainda são os determinantes de grande número de mortes. Adicionalmente, o uso muitas vezes indiscriminado, de antibióticos determina aumento da incidência de patógenos microbianos antibiótico-resistentes ${ }^{(19,24,35)}$.

Bactérias comensais, como Enterococcus faecalis e Escherichia coli, estão relacionadas ao câncer colorretal desde que os sítios dessas neoplasias intestinais coincidam com as regiões em que essas bactérias estejam presentes em grandes quantidades ${ }^{(30)}$.

\section{O CÂNCER DE CÓLON E RETO}

Em termos de incidência, a neoplasia de cólon e de reto é a terceira causa mais comum de câncer no mundo em ambos os sexos e a segunda causa em países desenvolvidos ${ }^{(31)}$. Possui índice de sobrevida de 5 anos em $63 \%$ dos casos, reduzindo a $10 \%$ naqueles com diagnóstico de metástases ${ }^{(20)}$. Esse tipo de neoplasia abrange tumores que atingem o cólon e o reto. De acordo com o INCA (Instituto Nacional de Câncer) (31), tanto homens como mulheres são igualmente afetados, sendo doença tratável e frequentemente curável, quando apenas localizada no intestino. O número de casos novos de câncer de cólon e reto estimado para o Brasil no ano de 2008 era de 12.490 casos em homens e de 14.500 em mulheres. Estes valores correspondiam a um risco aumentado de 13 casos novos a cada 100 mil homens e 15 para cada 100 mil mulheres. $\mathrm{O}$ fator de risco mais importante para este tipo de neoplasia é a história familiar de câncer de cólon e reto e predisposição genética ao desenvolvimento de doenças crônicas do intestino (como as poliposes adenomatosas), além de dieta com base em gorduras animais, baixa ingestão de frutas, vegetais e cereais, assim como consumo excessivo de álcool e tabagismo. A idade também é considerada fator de risco, uma vez que tanto a incidência como a mortalidade é maior com o aumento da idade. A prática de atividade física regular está associada a baixo risco de desenvolvimento do câncer de cólon e reto ${ }^{(31)}$.

Alguns mecanismos explicam como as bactérias contribuem para sua patogenicidade, sendo um deles a presença de alterações na microflora intestinal que facilitam o desenvolvimento de processos inflamatórios ${ }^{(22)}$. Outro fator contribuinte é a promoção da ativação de componentes carcinogênicos e a produção de compostos mutagênicos, como os radicais livres ${ }^{(30)}$.

\section{MECANISMO DE AÇÃO DOS AGENTES PROBIÓTICOS E PREBIÓTICOS NO CÂNCER COLORRETAL}

O consumo de produtos laticínios fermentados pode oferecer algum efeito protetor contra adenomas ou carcinomas do cólon ${ }^{(47)}$. Pressupõe-se que microorganismos selecionados seriam capazes de proteger o hospedeiro contra atividades carcinogênicas, através de três mecanismos ${ }^{(43,51)}$ : 
1. Os probióticos seriam capazes de inibir as bactérias responsáveis por converter substâncias pré-carcinogênicas (como os hidrocarbonetos policíclicos aromáticos e nitrosaminas) em carcinogênicas;

2. Estudos em animais de laboratório têm demonstrado que alguns probióticos inibem diretamente a formação de células tumorais;

3. Algumas bactérias da flora intestinal têm mostrado capacidade de ligação e/ou inativação carcinogênica.

Hirayama e Rafter ${ }^{(26)}$ e Rafter $^{(48)}$ sugerem vários mecanismos de atuação, incluindo o estímulo da resposta imune do hospedeiro (por aumentar a atividade fagocitária, a síntese de $\operatorname{IgA}$ e a ativação de linfócitos $\mathrm{T}$ e B), a ligação e a degradação de compostos com potencial carcinogênico, alterações qualitativas e/ou quantitativas na microbiota intestinal envolvidas na produção de carcinógenos e de promotores (ex: degradação de ácidos biliares), produção de compostos antitumorígenos ou antimutagênicos no cólon (como o butirato), alteração da atividade metabólica da microbiota intestinal, alteração das condições físico-químicas do cólon com diminuição do $\mathrm{pH}$ e efeitos sobre a fisiologia do hospedeiro. Outras evidências também sugerem que os probióticos reduzem a resposta inflamatória (com diminuição das citocinas, da hipersensibilidade e aumento da atividade fagocitária), alteram a atividade metabólica das bactérias intestinais e reduzem o número de bactérias envolvidas na pró-carcinogênese e na mutagênese ${ }^{(14,17,42)}$.

Existem referências quanto à habilidade que os lactobacilos e as bifidobactérias teriam em modificar a flora intestinal e diminuir o risco de câncer pela suas possíveis capacidades de diminuir as enzimas $\beta$-glicuronidase e nitroredutase, produzidas por bactérias patogênicas. A redução dessas enzimas leva à hidrólise de compostos carcinogênicos, diminuindo, assim, as substâncias nocivas ${ }^{(14,29)}$. Estudos em animais revelaram que o consumo de iogurtes reduziu a atividade dessas enzimas, indicando possível mecanismo pelo qual os probióticos podem prevenir o câncer colorretal ${ }^{(14)}$. Rowland et al. ${ }^{(53)}$ concluiram que ratos tratados com $B$. longum reduziram em $30 \%$ a atividade da $\beta$-glicuronidase, enquanto redução de $55 \%$ foi observada naqueles tratados com o probiótico B. longum combinado ao prebiótico inulina, comprovando assim, melhor eficácia quando utilizados os simbióticos. Em concordância, estudos em humanos mostraram que o consumo de Lactobacillus casei Shirota e Lactobacillus acidophilus também reduziu significativamente a atividade dessas enzimas ${ }^{(21,57)}$. Resultados similares foram obtidos por Lidbeck et al. ${ }^{(37)}$, que suplementaram a dieta de 14 pacientes com câncer de cólon com L. acidophilus (aproximadamente $3 \times 10^{11}$ lactobacilos por dia), por período de 6 semanas e obtiveram redução de $14 \%$ na atividade da enzima $\beta$-glicuronidase.

Evidências mais diretas para as propriedades protetoras de probióticos e prebióticos contra o câncer englobam a prevenção de danos e mutações do DNA, considerado evento primário no processo de carcinogênese ${ }^{(10)}$. Ratos alimentados com dieta contendo 3\% do prebiótico lactulose e tratados com o carcinógeno DMH (1,2-dimetilhidrazina) apresentaram menores danos ao DNA de células do cólon, quando comparados com ratos alimentados com sacarose, sendo que nestes animais a percentagem de células com danos graves no DNA foi de $33 \%$, comparado com apenas $12,6 \%$ daqueles tratados com lactulose ${ }^{(52)}$. Estes resultados evidenciam que tanto os probióticos quanto os prebióticos possuem efeitos protetores contra os estágios iniciais de câncer de cólon ${ }^{(10)}$.

A literatura também salienta que criptas aberrantes constituem lesões precursoras putrefativas, a partir das quais os adenomas e carcinomas podem se desenvolver no cólon. Estudos com ratos mostram que a administração de prebióticos na dieta, como a oligofrutose e inulina, suprimiu significativamente o número de focos de criptas aberrantes no cólon, quando comparado à dieta controle. $\mathrm{O}$ papel desempenhado pela inulina e pela oligofrutose na redução da formação das criptas aberrantes, marcador pré-neoplásico precoce do potencial maligno no processo de carcinogênese do cólon, sugere que elas tenham potencial para suprimir tal evento. Essa prevenção, provavelmente, ocorre pela modificação da microbiota do cólon ${ }^{(36,50)}$. Rowland et al. ${ }^{(53)}$, mostraram que a administração em conjunto de probióticos e prebióticos reduziu focos de criptas aberrantes em 59\%, com menor efeito quando oferecidos individualmente.

\section{UTILIZAÇÃO DOS PROBIÓTICOS, PREBIÓTICOS E SIMBIÓTICOS EM PACIENTES COM NEOPLASIA DE CÓLON E RETO}

Há ainda estudos epidemiológicos, como o de Young e Wolf ${ }^{(61)}$ que mostraram associação inversa entre consumo de probióticos em leites fermentados e câncer de cólon em 353 indivíduos com diagnóstico dessa doença. Estudo semelhante conduzido por Peters et al. ${ }^{(46)}$ mostrou efeito protetor contra o câncer de cólon em 746 pacientes que ingeriram iogurte acrescentado de probióticos.

No Japão, alguns autores examinaram a hipótese de a administração de fibras e probióticos (Lactobacillus casei) prevenir a ocorrência de câncer de cólon em população com risco de desenvolvimento de lesões intestinais, após remoção de pelo menos dois adenomas. Não encontraram diferença significante no desenvolvimento de novas lesões de cólon entre 2 e 4 anos. Entretanto, após seguimento de 4 anos, a ocorrência de lesões de moderada e elevada intensidade, foi significativamente reduzida no grupo que recebeu $L$. casei, diminuindo assim, as chances de progredir para um câncer de cólon ${ }^{(32)}$.

Quanto ao uso de simbióticos, o estudo conduzido em 2007 por Rafter et al. ${ }^{(4)}$, com 37 pacientes com câncer de cólon e 43 pacientes polipectomizados, teve como objetivo verificar se o uso de simbióticos (oligofrutose e inulina - SYN1 + Lactobacillus rhamnosus $G G-\mathrm{LGG}+$ Bifidobacterium lactis Bb12 - BB12) reduziria o risco de câncer de cólon em humanos. Os resultados mostraram que os simbióticos alteraram a flora fecal, aumentando as bifidobactérias e os lactobacilos e reduzindo Clostridium perfringens. A intervenção 
também reduziu significantemente a proliferação das células neoplásicas, a capacidade de necrose e aumentou a produção de interferon gama nos pacientes com câncer, além de promover uma barreira epitelial e prevenir a secreção de interleucina 2 nos pacientes polipectomizados.

Em voluntários que receberam Lactobacillus acidophillus ou Lactobacillus casei, foi observada redução dos níveis de enzimas conversoras de substâncias pré-carcinogênicas em carcinogênicas a nível de suas floras intestinais ${ }^{(25,38)}$.

Em publicação de $2007^{(9)}$, comparando pacientes com diagnóstico de neoplasias hematológicas malignas, submetidos a altas doses de quimioterapia e distribuídos aleatoriamente em um grupo controle, medicado com maltodextrina (placebo) e um outro tratado com FOS, os autores concluiram que as taxas de proteína $\mathrm{C}$ reativa foram estatisticamente superiores no grupo controle, indicando a ocorrência de processos inflamatórios e maior demanda metabólica, sugerindo que a quantidade de FOS pode ter favorecido a redução deste quadro no grupo suplementado, confirmado pela correlação negativa entre estas variáveis. Outro estudo, também realizado com pacientes com diagnóstico de neoplasias hematológicas, concluiu que a suplementação do prebiótico FOS foi capaz de aumentar a quantidade de bifidobactérias e não promoveu a diminuição do $\mathrm{pH}$ fecal ${ }^{(8)}$.

Sabe-se também que um dos efeitos colaterais presente nos tratamentos de câncer, como na radioterapia, envolvendo principalmente a região da pelve, é a ocorrência de diarreia. Assim sendo, em estudo de pacientes em radioterapia com comprometimento da pelve, a utilização do Lactobacillus acidophillus NDCO 1748, proporcionou diminuição significante da diarreia nesses indivíduos ${ }^{(54)}$. Em concordância, estudo duplo-cego em pacientes com neoplasia de cólon ${ }^{(15)}$, mostrou que o grupo placebo apresentou mais episódios de diarreia induzida pela radioterapia, em relação àquele que recebeu probióticos VSL\#3 (51,8\% e 31,6\%, respectivamente; $P<0,001)$, concluindo que o uso de bactérias probióticas é método fácil e seguro de proteção aos pacientes com câncer.

\section{ANÁLISE E PERSPECTIVAS DE APLICAÇÃO DESTES AGENTES NO CÂNCER COLORRETAL}

A existência de uma microbiota intestinal saudável resulta em correto desempenho das funções fisiológicas do hospedeiro e propicia melhor qualidade de vida aos indivíduos. A presença de doenças que alteram e provocam desequilíbrio desta microbiota intestinal, como câncer de cólon, torna-se grande desafio no campo da nutrição para que esse quadro seja revertido. Sendo assim, estudos têm sido realizados evidenciando o papel exercido pelos probióticos e prebióticos tanto na prevenção como no tratamento dessas neoplasias, sendo que a combinação de ambos (simbióticos) também apresenta grande eficácia.

Os possíveis mecanismos pelos quais os probióticos e prebióticos atuam no câncer de cólon englobam: aumento da resposta imune, redução da resposta inflamatória, inibição de formação de células tumorais e da conversão de substâncias pré-carcinogênicas em carcinogênicas.

Numerosos estudos in vitro e em modelos experimentais já destacaram o potente uso dos probióticos e prebióticos como agentes moduladores da carcinogênese. No entanto, ainda é baixo o número de indivíduos que cumprem com essa recomendação, sendo os profissionais de saúde responsáveis por manter e disseminar conhecimentos atualizados sobre o tema e colocar em prática seu uso. Portanto, mais estudos, e de caráter intervencional, em humanos, ainda se faz necessário a fim de potencializar essa nova estratégia de prevenção e tratamento de câncer de cólon.

Denipote FG, Trindade EBSM, Burini RC. Probiotics and prebiotics in primary care for colon cancer. Arq Gastroenterol. 2010;47(1):93-8.

ABSTRACT - Context - Colon neoplasias are presently the third most common cancer type. Its treatment is still associated with high risk of complications, thus emphasizing the need to design new treatment strategies. The ingestion of probiotics and prebiotics, or the combination of both (symbiotics), represents a new therapeutic choice. In front of the importance among qualitative and quantitative balance in intestinal microbiota for human's health and with the purpose to evaluate the application of probiotics and prebiotics, this study tries to approach the importance of these in both the prevention and treatment of colon cancer. Evidence acquisition - A study was conducted on scientific databases (Medline, Lilacs, PubMed, Ovid, SciELO), and a review was made of recent scientific articles in the literature, from 2003 to 2008 . Additional informations were taken from sites in the internet. Results - Studies point out the inverse relation between the consumption of probiotics and prebiotics in colon cancer diagnosis through various action mechanisms, including: immune response stimulation, reduction in inflammation, for directly inhibiting the formation of tumor cells and for converting pre-carcinogenic substances into carcinogenic ones. Conclusion - Through this literature review, it was possible to achieve positive answers as regards the use of probiotics and prebiotics in carcinogenesis, which can be adequately recommended.

HEADINGS - Probiotics. Prebiotics. Simbiotics. Colonic neoplasms.

\section{REFERÊNCIAS}

1. Alexander M. Microbial ecology. New York: John Wiley; 1971.

2. Bengmark S. Ecological control of the gastrointestinal tract. The role of probiotic flora. Gut. 1998;42:2-7.
3. Bengmark S, Lorenzo AG, Culebras MJ. Use of pro, pre and symbiotics in the ICU-future options. Nutr Hosp. 2001;16:239-56.

4. Berg R. The indigenous gastrointestinal microflora. Trends microbiol. 1996;4:430-5.

5. Bielecka M, Biedrzycka E, Majkowska A. Selection of probiotics and prebiotics for synbiotics and confirmation of their in vivo effectiveness. Food Res Int. 2002;35:125-31. 
6. Blaut M. Relationship of probiotics and food to intestinal microflora. Eur J Nutr 2002;41:11-6.

7. Bourlioux P, Koletzko B, Guarner F, Braesco V. The intestine and its microflora are partners for the protection of the host: report on the danone symposium "The intelligent intestine". Am J Clin Nutr. 2003;78:675-83.

8. Burigo T, Fagundes RLM, Trindade EBSM, Vasconcelos HCFF. Efeito bifidogênico do frutooligossacarídeo na microbiota intestinal de pacientes com neoplasia hematológica. Rev Nutr. 2007;20:491-7.

9. Burigo T, Fagundes RLM, Trindade EBSM, Vasconcelos HCFF, Massaut IHB, Rotolo MAS. Ação do prebiótico sobre as proteínas de fase aguda de pacientes com neoplasia hematológica. Rev Bras Hematol Hemoter. 2007;29:130-5.

10. Burns AJ, Rowland IR. Anti-carcinogenicity of probiotics and prebiotics. Curr Issues Intest Microbiol. 2002;1:13-24.

11. Charterisis WP, Kelly PM, Morelli L, Collins JK. Ingredient selection criteria for probiotic microorganisms in functional dairy foods. Int J Dairy Technol. 1998;51:123-36.

12. Cummings JH, Macfarlane GT. Gastrointestinal effects of prebiotics. Br J Nutr 2002;87:145-51.

13. Daly JM, Hoffman K, Lieberman M, Leon P, Redmond HP, Shou J, Torosian MH. Nutritional support in the cancer patient. JPEN J Parenter Enteral Nutr. 1990;14(suppl 5):244s-8s.

14. de Moreno de LeBlanc A, Perdigon G. Reduction of beta-glucuronidase and nitroreductase activity by yoghurt in a murine colon cancer model. Biocell. 2005;29:15-24.

15. Delia P, Sansotta G, Donato V, Frosina P, Messina G, De Renzis C, Famularo G. Use of probiotics for prevention of radiation-induced diarrhea. World J Gastroenterol. 2007;13:912-5.

16. Fuller R. Probiotics in human medicine. Gut. 1991;32:439-42.

17. Gaudier E, Michel C, Segain JP, Cherbut C, Hoebler C. The VSL\#3 probiotic mixture modifies microflora but does not heal chronic dextran-sodium sulfateinduced colitis or reinforce the mucus barrier in mice. J Nutr. 2005;135:2753-61.

18. Gibson GR, Roberfroid MB. Dietary modulation of human colonic microbiota: introducing the concept of the prebiotics. J Nutr. 1995;125:1401-12.

19. Gibson GR. Dietary modulation of the human gut microflora using the prebiotics oligofructose and inulin. J Nutr. 1999;129:1438s-41s.

20. Goldberg RM. Advances in the treatment of metastatic colorectal cancer Oncologist. 2005;10:40-8.

21. Goldin BR, Swenson L, Dwyer J, Sexton M, Gorbach SL. Effect of diet and Lactobacillus acidophilus supplements on human fecal bacterial enzymes. J Natl Cancer Inst. 1980;64:255-61.

22. Guarner E, Malagelada JR. Gut flora in health and disease. Lancet. 2003;361:512-9.

23. Hart AL, Stagg AJ, Frame M, Graffner H, Glise H, Falk P, Kamm MA. The role of the gut flora in health and disease, and its modification as therapy. Aliment Pharmacol Ther. 2002;16:1383-93.

24. Havena ARR, Huis in’t Veld JHK. Probiotics: a general view. In: Wood B, editor. The lactic acid bacteria in health and disease. London: Elsevier Applied Science; 1992. p.209-24.

25. Hayatsu H, Hayatsu T. Supressing effect of Lactobacillus casei administration on the urinary mutagenicity arising from ingestion of fried ground beef in the human. Cancer Lett. 1993;73:173-9.

26. Hirayama K, Rafter J. The role of probiotic bacteria in cancer prevention. Microbes Infect. 2000;2:681-6.

27. Holzapfel WH, Schillinger U. Introduction to pre and probiotics. Food Res Int. 2002;35:109-16.

28. Hopkins MJ, MacFarlane GT. Nondisgestible oligosaccharides enhance bacterial colonization resistance against Clostridium difficile in vitro. Appl Environ Microbiol. 2003;69:1920-7.

29. Hosoda M, Hashimoto H, He F, Morita H, Hosono A. Effect of administration of milk fermented with Lactobacillus acidophilus LA-2 on fecal mutagenecity and microflora in the human intestine. J Dairy Sci. 1996;79:745-49.

30. Huycke MM, Gaskins HR. Commensal bacteria, redox stress, and colorectal cancer: mechanisms and models. Exp Biol Med. 2004;229:586-97.

31. Instituto Nacional do Câncer. Estimativa 2008: incidência de câncer no Brasil. Rio de Janeiro: INCA; 2007. Disponível em: http://www.inca.gov.br/estimativa/2008/ index.aps?link=conteudo_view.asp\&ID $=1$.

32. Ishikawa H, Akedo I, Otani T, Suzuki T, Nakamura T, Takeyama I, Ishiguro S, Miyaoka E, Sobue T, Kakizoe T. Randomized trial of dietary fibre and Lactobacillus casei administration for prevention of colorectal tumors. Int $\mathbf{J}$ Cancer. 2005; 116:762-7.

33. Isolauri E. Probiotics for infectious diarrhea. Gut. 2003; 52:436-7.

34. Isolauri E, Salminen S, Ouwehand AC. Probiotics. Best Pract Res Clin Gastroenterol. 2004;8:299-313.
35. Karkow FJA, Faintuch J, Karkow AGM. Probióticos: perspectives médicas. Rev AMRIGS. 2007;51:38-48.

36. Kaur N, Gupta AK. Applications of inulin and oligofructose in health and nutrition. J Biosci. 2002;27:703-14.

37. Lidbeck A, Geitner Allinger U, Orrhage KM, Ottova L, Brismar B, Gustafsson JA, Rafter JJ, Nord CE. Impact of Lactobacillus acidophilus supplements on the faecal microflora and soluble faecal bile acids in colon cancer patients. Microbiol Ecol Health Dis. 1991;4:81-8.

38. Lidbeck A, Nord CE, Gustafsson JA, Rafter JJ. Lactobacilli anticarcinogenic activities and human intestinal microflora. Eur J Cancer Prev. 1992;1:341-53.

39. Lilly DM, Stillwell RH. Probiotics: growth-promoting factors produced by micro-organisms. Science. 1965;147:747-8.

40. Mattila-Sandholm T, Myllärinen P, Crittenden R, Mogensen G, Fondén R, Saarela M. Technological challenges for future probiotic foods. Int Dairy J. 2002; $12: 173-82$.

41. Metchnikoff E. The prolongation of life. London: Heinemann; 1907.

42. O’Mabony L, Feeney M, O'Halloran S, Murphy L, Kiely B, Fitzgibbon J, Lee G, O’Sullivan G, Shanahan F, Collins JK. Probiotic impact on microbial flora, inflammation and tumor development in IL-10 knockout mice. Aliment Pharmacol Ther. 2001;15:1219-25.

43. Orrhage K, Sillerstrom E, Gustafsson JA, Nord C, Rafter JJ. Binding of mutagenic heterocyclic amines by intestinal and lactic acid bacteria. Mutat Res. 1994;311: 239-48.

44. Passos LML, Park YK. Frutooligossacarídeos: implicações na saúde humana e utilização em alimentos. Cienc Rural. 2003;33:385-90.

45. Peris GP, Lesmes B, Cuerda CM, Alvarez C. Metabolismo colônico de la fibra. Nutr Hosp. 2002;17:11-6.

46. Peters RK, Pike MC, Garabrant D, Mack TM. Diet and colon cancer in Los Angeles Country, California. Cancer Causes Control. 1992;3:457-73.

47. Rafter J. The role of lactic acid bacteria in colon cancer prevention. Scand J Gastroenterol. 1995;30:497-502.

48. Rafter J. Probiotics and colon cancer. Best Pract Res Clin Gastroenterol. 2003; $17: 849-59$.

49. Rafter J, Bennett M, Caderni G, Clune Y, Hughes R, Karlsson PC, Klinder A, O’Riordan M, O’Sullivan GC, Pool-Zobel B, Rechkemmer G, Roller M, Rowland I, Salvadori M, Thijs H, Van Loo J, Watzl B, Collins JK. Dietary synbiotics reduce cancer risk factors in polypectomized and colon cancer patients. Am J Clin Nutr. 2007:85:488-96.

50. Roberfroid MB. Functional food concept and its application to prebiotics. Dig Liver Dis. 2002;34:s105-s10.

51. Rowland IR, Grasso P. Degradation of N-nitrosamines by intestinal bacteria. Appl Microbiol. 1975;29:7-12.

52. Rowland IR, Bearne CA, Fisher R, Pool-Zobel BL. The effect of lactulose on DNA damage induced by DMH in the colon of human flora-associated rats. Nutr Cancer. 1996;26:37-47.

53. Rowland IR, Rumney CJ, Coutts JT, Lievense LC. Effect of Bifidobacterium longum and inulin on gut bacterial metabolism and carcinogen-induced aberrant crypt foci in rats. Carcinogenesis. 1998;19:281-5.

54. Salminen E, Eloma AI, Minkkinen J, Vapaatalo H, Salminen S. Preservation of intestinal integrity during radiotherapy using live Lactobacillus acidophilus cultures. Clin Radiol. 1988;39:43-57.

55. Sanders ME. Probiotics: considerations for human health. Nutr Rev. 2003;61: 91-9.

56. Schrezenmeir J, Vrese M. Probiotics, prebiotics, and synbiotics-approaching a definition. Am J Clin Nutr. 2001;73:s361-s4.

57. Spanhaak S, Havenaar R, Schaafsma G. The effect of consumption of milk fermented by Lactobacillus casei strain Shirota on the intestinal microflora and immune parameters in humans. Eur J Clin Nutr. 1998;52:899-907.

58. Suchner U, Senftleben U, Eckart T, Sholz MR, Beck K, Murr R, Enzenbach R, Peter K. Enteral versus parenteral nutrition: effects on gastrointestinal function and metabolism. Nutrition. 1996;12:13-22.

59. Watzl B, Girrbacch S, Roller M. Inulin, oligofructose and immunomodulation. Br J Nutr. 2005;93:49-55.

60. Whitney E, Rolfes SR. Entendendo os nutrientes. 10a ed. São Paulo: Cengage Learning; 2008.

61. Young TB, Wolf DA. Case-control study of proximal and distal colon cancer and diet in Wisconsin. Int J Cancer. 1988;42:167-75.

62. Yun JW. Fructooligosaccharides - Occurrence, preparation and applications. Enzyme Microb Technol. 1996;19:107-17.

Received 3/10/2008 Accepted 15/5/2009. 